\title{
Enhanced Performance of DSSCs Based on the Insertion Energy Level of CdS Quantum Dots
}

\author{
Xiaoping Zou and Zhe Sun \\ Research Center for Sensor Technology, Beijing Key Laboratory for Sensor, Ministry-of-Education Key Laboratory for \\ Modern Measurement and Control Technology, School of Applied Sciences, Beijing Information Science and Technology University, \\ Jianxiangqiao Campus, Beijing 100101, China \\ Correspondence should be addressed to Xiaoping Zou; xpzou2005@gmail.com
}

Received 14 February 2014; Accepted 29 April 2014; Published 22 May 2014

Academic Editor: Shunsheng Cao

Copyright (C) 2014 X. Zou and Z. Sun. This is an open access article distributed under the Creative Commons Attribution License, which permits unrestricted use, distribution, and reproduction in any medium, provided the original work is properly cited.

Cadmium sulfide (CdS) quantum dots (QDs) are assembled onto the $\mathrm{TiO}_{2}$ films by chemical bath deposition method (CBD). And the QDs size is controlled by the times of CBD cycles. They are characterized by UV-visible absorption. To avoid the photo corrosion and electrolyte corrosion, $\mathrm{CdS}$ and N719 are sequentially assembled onto the nanocrystalline $\mathrm{TiO}_{2}$ films to prepare a CdS/N719 cosensitized photo electrode for the dye-sensitized solar cells. In the structure of $\mathrm{TiO}_{2} / \mathrm{CdS} / \mathrm{N} 719$ electrode, the reorganization of energy levels between CdS and N719 forms a stepwise structure of band-edge levels which is advantageous to the electron injection and hole recovery of CdS and N719 QDs. The open circuit voltage $\left(V_{\mathrm{oc}}\right)$, short circuit current density $\left(J_{\mathrm{sc}}\right)$, and efficiency are increased.

\section{Introduction}

Due to its renewable and clean-energy characteristics, solar energy is destined to be an important energy source for the next generation. Recently, dye-sensitized solar cells (DSSCs) have attracted lots of attention because of their lower cost compared to the silicon based solar cells. DSSCs are based on photosensitization of mesoporous $\mathrm{TiO}_{2}$ films by absorbed sensitizers. The molecular engineering of porphyrin sensitizers is recently used in DSSCs and energy conversion efficiencies up to $13 \%$ have been reported [1]. In addition to organic dyes, semiconductor quantum dots (QDs) which absorb light in the visible spectrum are also good candidates to be a sensitizer of a DSSC cell. And there are some specific advantages of using semiconductor QDs as sensitizers. Due to the quantum confinement effect, the optical property and the band gap of a QD can be adjusted by changing the size of the QDs [2-4]. In addition, the QDs open up a way to utilize hot electrons and to generate multiple electron-hole pairs with a single photon through impact ionization $[5,6]$. But there are some disadvantages about the QDs, such that the QDs often undergo photo corrosion and electrolyte corrosion $[7,8]$. And we know that certain organic molecules are able to reduce the corrosions $[7,9]$. In this work, we make the $\mathrm{TiO}_{2}$ sensitized by both CdS QDs and the N719 in DSSCs to improve the performance of DSSC and also to explore the principles involved.

\section{Experimental}

In our experiment, F-doped tin oxide was used as the substrate. Firstly, FTO glass substrates were ultrasonically soaked in deionized water, acetone, and absolute ethanol subsequently. Then the glass was soaked into the $\mathrm{TiCl}_{4}$ solution with the concentration of $0.04 \mathrm{~mol} / \mathrm{L}$ for $30 \mathrm{~min}$ at $70^{\circ} \mathrm{C}$. The $\mathrm{TiO}_{2}$ was coated on the FTO substrates and then sintered at $450^{\circ} \mathrm{C}$ for $30 \mathrm{~min}$. The thickness of the $\mathrm{TiO}_{2}$ film was $8 \mu \mathrm{m}$ which was controlled by the times of the screen printing. Here we used chemical bath deposition (CBD) to assemble QDs onto the $\mathrm{TiO}_{2}$ photoelectrode. And the particle size of QDs was controlled by adjusting the dipping time. The $\mathrm{TiO}_{2}$ film was firstly dipped into the $\mathrm{Cd}\left(\mathrm{NO}_{3}\right)_{2}$ ethanol solution $(0.3 \mathrm{M})$ for $5 \mathrm{~min}$, rinsed with the ethanol, and then dipped for another $5 \mathrm{~min}$ in the $\mathrm{Na}_{2} \mathrm{~S}$ ethanol solution $(0.1 \mathrm{M})$ and rinsed again with the ethanol. This is called one cycle, 


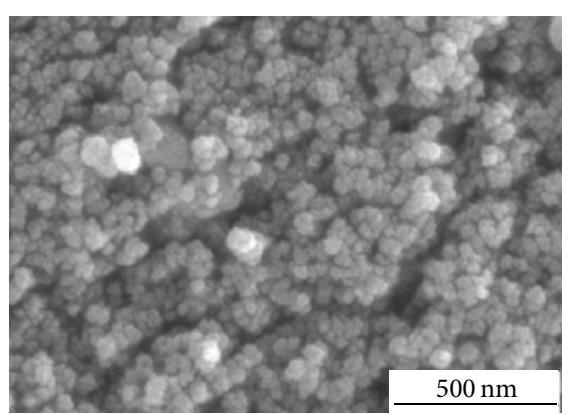

(a)

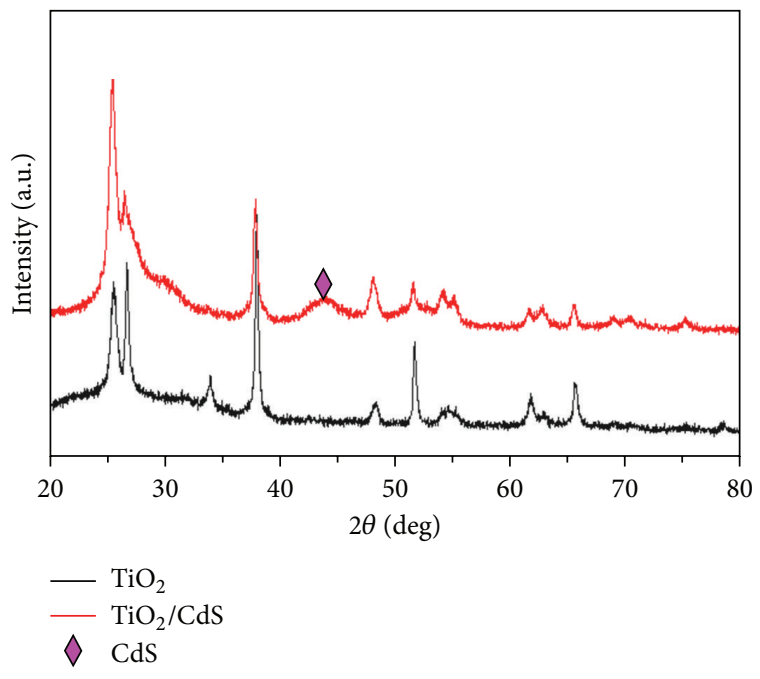

(c)

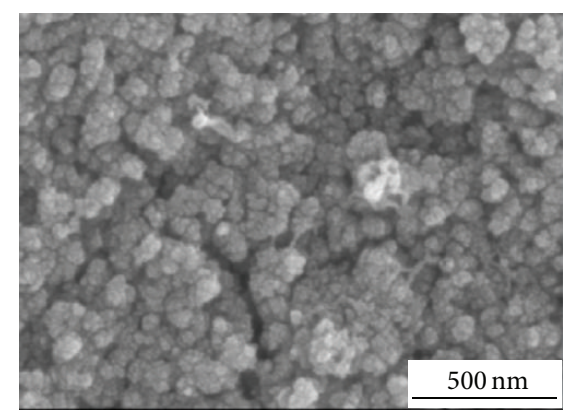

(b)

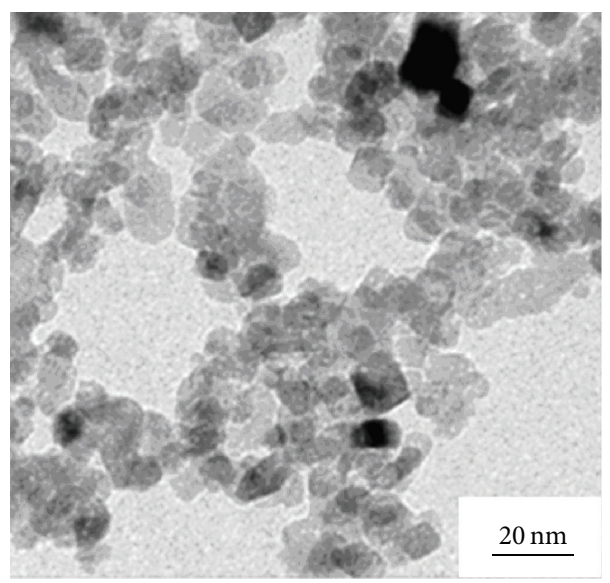

(d)

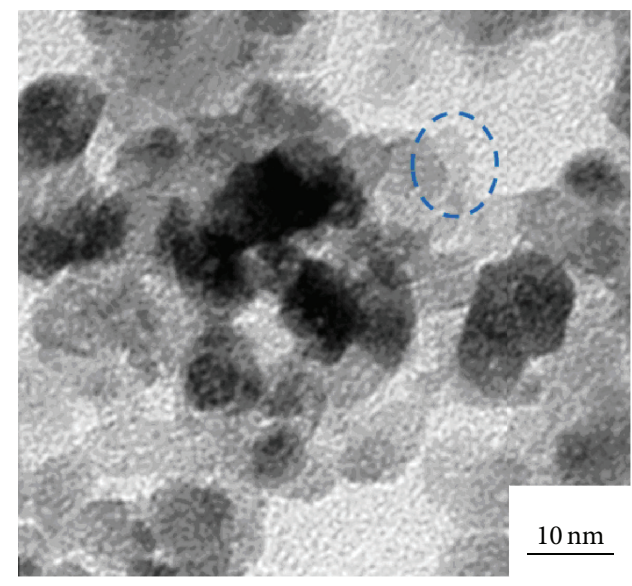

(e)

FIGURE 1: SEM of $\mathrm{TiO}_{2}$ with different amount of CdS, (a) 4 CBD cycles of CdS, (b) 10 CBD cycles of CdS, (c) typical XRD patterns, and (d) and (e) typical TEM images of the photo anode.

and here we assembled QDs for 2 10 cycles to discuss the effect of the particle size on the light absorbance. For the total dissolution of the solute, the ethanol and the deionized water are mixed as the solvent in which the proportion of the volume is $7: 3$.

The $\mathrm{TiO}_{2}$ film with CdS QDs was soaked in the N719 for 44 hours. Then the $\mathrm{TiO}_{2}$ electrodes were incorporated into thin-layer sandwich-type cells with Pt-coated FTO as counter electrode and electrolyte solution. The working area of the sample was $0.25 \mathrm{~cm}^{2}$. The surface morphology of the samples was conducted with the SEM. Optical absorption spectra of the $\mathrm{TiO}_{2}$ electrodes were recorded by a UV/VIS/NIR spectrophotometer. The photocurrent-voltage $(I-V)$ curves were measured by the electrochemical workstation under 


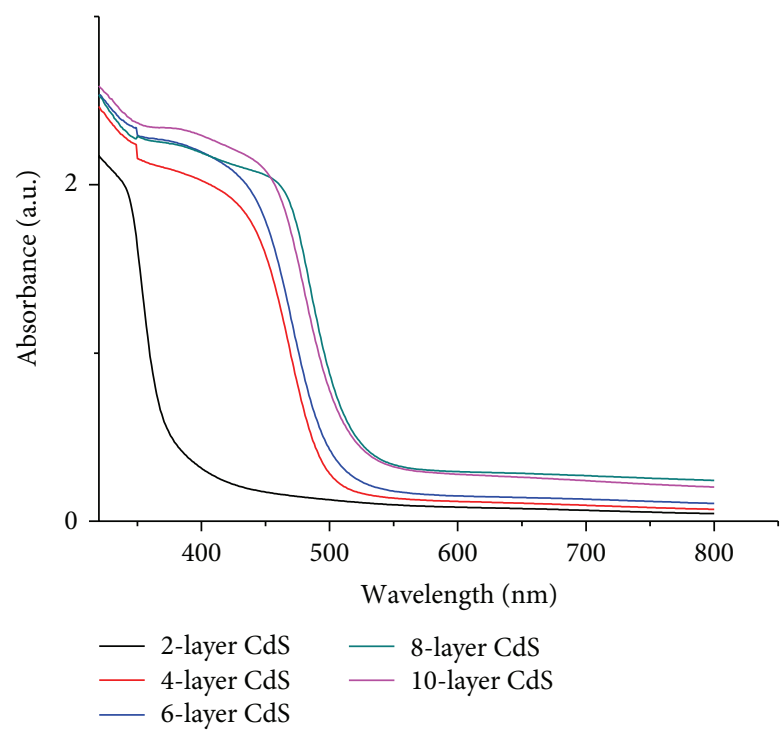

Figure 2: The absorbance spectra of $\mathrm{CdS} / \mathrm{TiO}_{2}$ films in the visible region.

an illumination of xenon lamp. The irradiance is $100 \mathrm{~mW} / \mathrm{cm}^{2}$ which is measured by a radiometer (FZ-A, Photoelectric Instrument Factory of Beijing Normal University).

\section{Results and Discussion}

The thickness of bare $\mathrm{TiO}_{2}$ film prepared using $\mathrm{TiO}_{2}$ powders of P25 was about $5 \mu \mathrm{m}$. Figure 1 shows the $\mathrm{SEM}$ of $\mathrm{TiO}_{2}$ with different amount of CdS, and (a) was $\mathrm{TiO}_{2}$ with $\mathrm{CdS}$ after 4 CBD cycles and (b) was 10 CBD cycles. From these images we can see that, with the increase cycles of the CdS, the interspaces of the $\mathrm{TiO}_{2}$ particles are becoming smaller and smaller; this result indicates that the CdS was assembled onto the surface of $\mathrm{TiO}_{2}$ particles, and the amount of the CdS QDs is increased with increasing CBD cycles. Figures 1(a) and 1(b) are $\mathrm{SEM}$ of $\mathrm{TiO}_{2}$ with different amount of CdS; Figures 1(c) to $1(\mathrm{e})$ are typical XRD patterns and TEM images of the photo anode.

Figure 2 shows the absorbance spectra of $\mathrm{CdS} / \mathrm{TiO}_{2}$ films in the visible region. From this figure we can see that, with the increase of the cycles of CdS, the absorbance intensities are becoming stronger and stronger, and this suggests the increased number of CdS QDs. The extrapolations at the absorption edges show a red shift in the spectra. The shift suggests a growth in QD size with increasing CBD cycles. And this can be explained by the decrease in band gap energy arising from the increasing particle size in the quantum size regime.

The parameters of QDSSCs were tabulated in Table 1, and the corresponding trend of the parameters with increasing CBD cycles was shown in Figure 3.

From Table 1 and Figure 3 we can see that with the increasing cycles of CBD, the short circuit current $\left(J_{\text {sc }}\right)$, open circuit voltage $\left(V_{\mathrm{oc}}\right)$, and the efficiency are improved before
TABLE 1: The parameters of QDSSCs with CBD cycles of 2 10.

\begin{tabular}{lcccc}
\hline Cycles of CBD & $J_{\text {sc }}\left(\mathrm{mA} / \mathrm{cm}^{2}\right)$ & $V_{\text {oc }}(\mathrm{V})$ & FF & Efficiencies $(\%)$ \\
\hline 2 & 1.592 & 0.433 & 0.41 & 0.285 \\
4 & 2.816 & 0.442 & 0.47 & 0.586 \\
6 & 3.91 & 0.483 & 0.39 & 0.745 \\
8 & 3.765 & 0.408 & 0.39 & 0.596 \\
10 & 3.672 & 0.403 & 0.30 & 0.438 \\
\hline
\end{tabular}

the CBD cycle is 6 and fill factor (FF) before 4, but these parameters are decreased with the continuing increase of CBD cycles. This suggests, with the increasing CBD cycles (before the cycles of 6), the size of the QDs is becoming larger and the energy level has been adjusted. This makes the $V_{\mathrm{oc}}$ increase with the increase of the CBD cycles. This is according to the absorbance spectra of $\mathrm{CdS} / \mathrm{TiO}_{2}$ films. And also the more CBD cycles are, the bigger $J_{\mathrm{sc}}$ is becoming, and this suggests the additional amount of CdS QDs. So is the efficiency. But when the CBD cycles are 8 or more, the $J_{\mathrm{sc}}$, $V_{\mathrm{oc}}$, FF, and efficiency are decreased. This may be because the spaces between the $\mathrm{TiO}_{2}$ particles are becoming blocked, and the electrolyte getting into the spaces is becoming harder, and this makes the hole and electron recombination easier, so the $J_{\text {sc }}$ decreases. This also causes the FF to decrease and so does the efficiency. So we can get the best efficiency with the CdS sensitized $\mathrm{TiO}_{2}$, which is $0.745 \%$ with the CBD cycle of 6 . But we can see that the efficiency is still low, and the QDs also undergo photo corrosion and electrolyte corrosion. So here we make the cosensitized DSSC.

Plots of photocurrent density against voltage of the cosensitized DSSC are shown in Figure 4. And the corresponding readings are tabulated in Table 2 . When the $\mathrm{TiO}_{2}$ was sensitized both by CdS and N719, the efficiency increases 


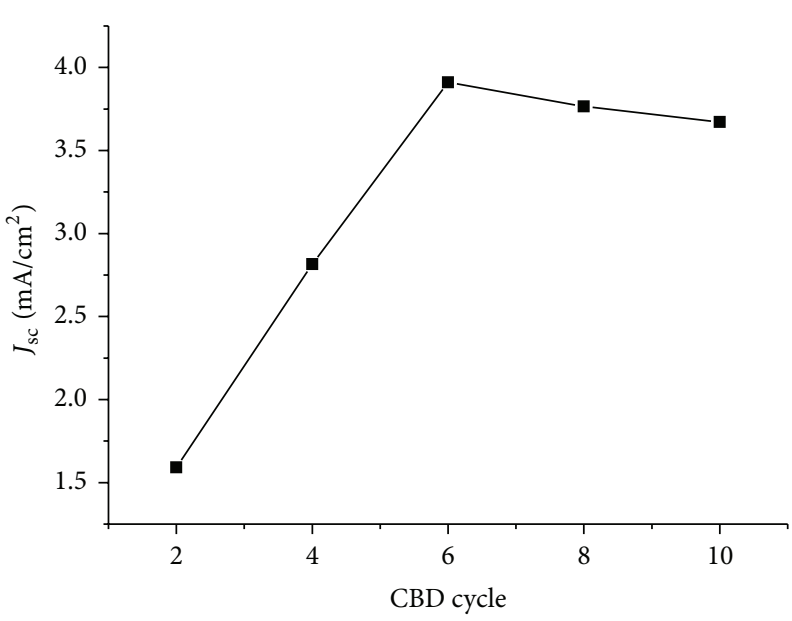

-- CdS

(a)

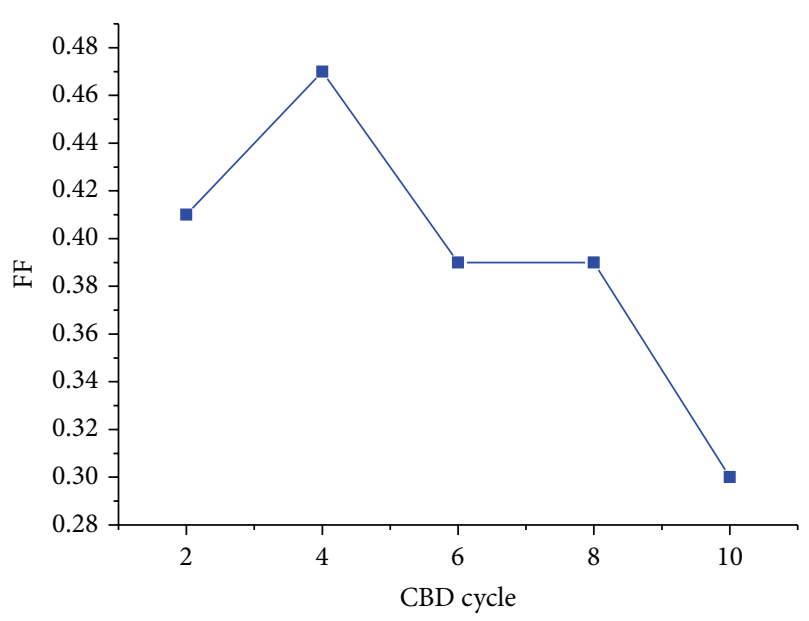

- CdS

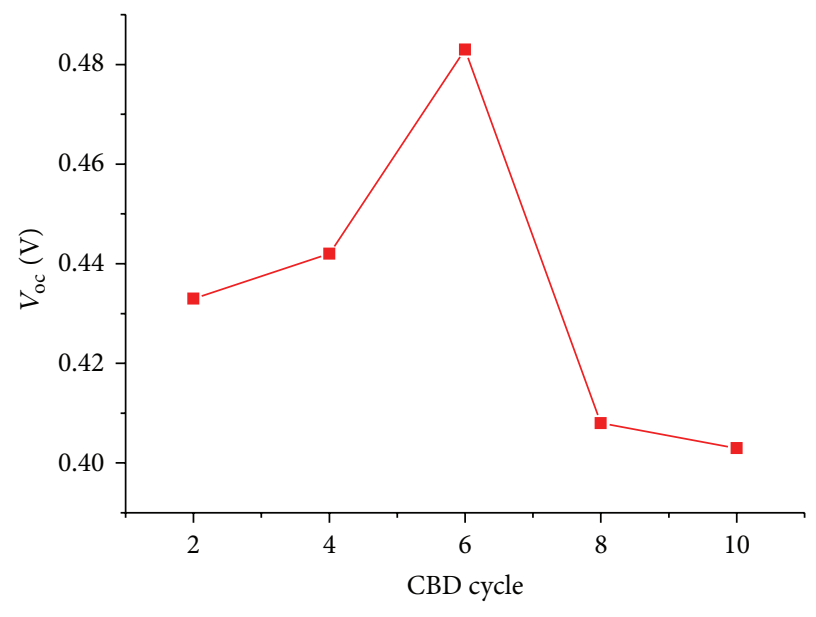

$-\square-\mathrm{CdS}$

(b)

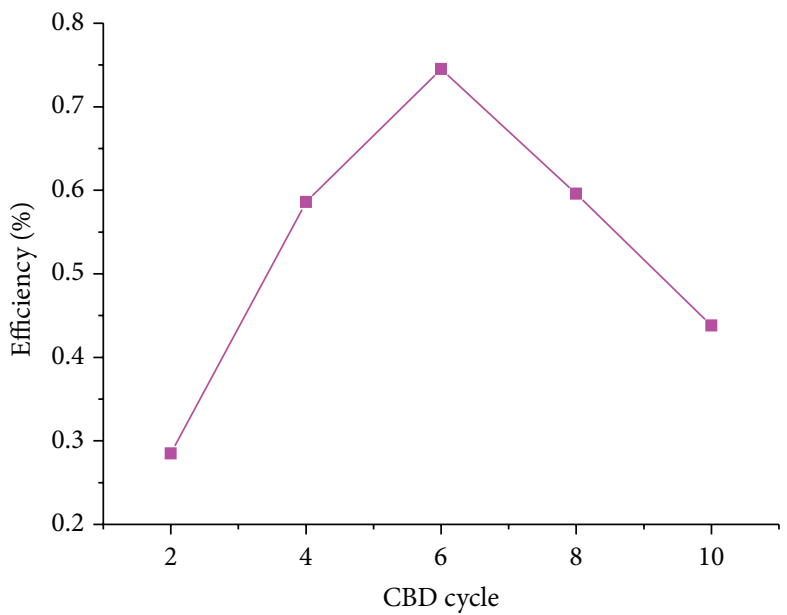

$-\mathrm{CdS}$

(c)

(d)

FIgURE 3: Trend of the $J_{\mathrm{sc}}, V_{\mathrm{oc}}$, FF, and efficiency with different CBD cycles.

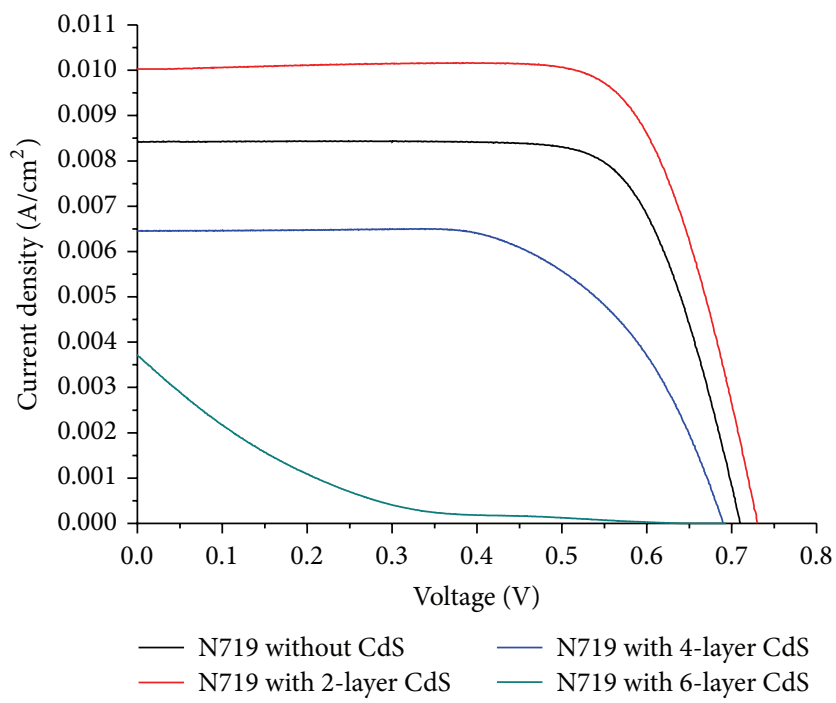

FIGURE 4: $J-V$ curves of N719-sensitized DSSC and N719 and CdS cosensitized DSSCs. 


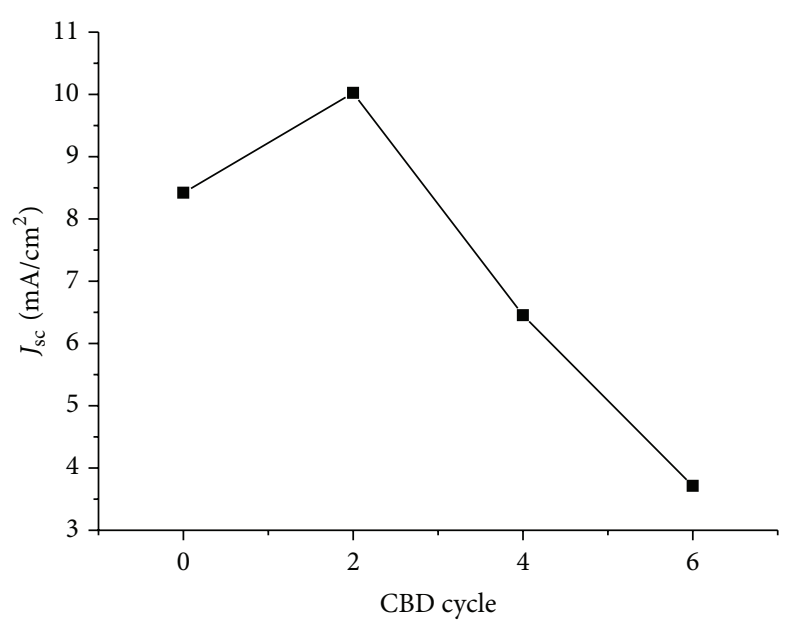

$--\mathrm{N} 719+\mathrm{CdS}$

(a)

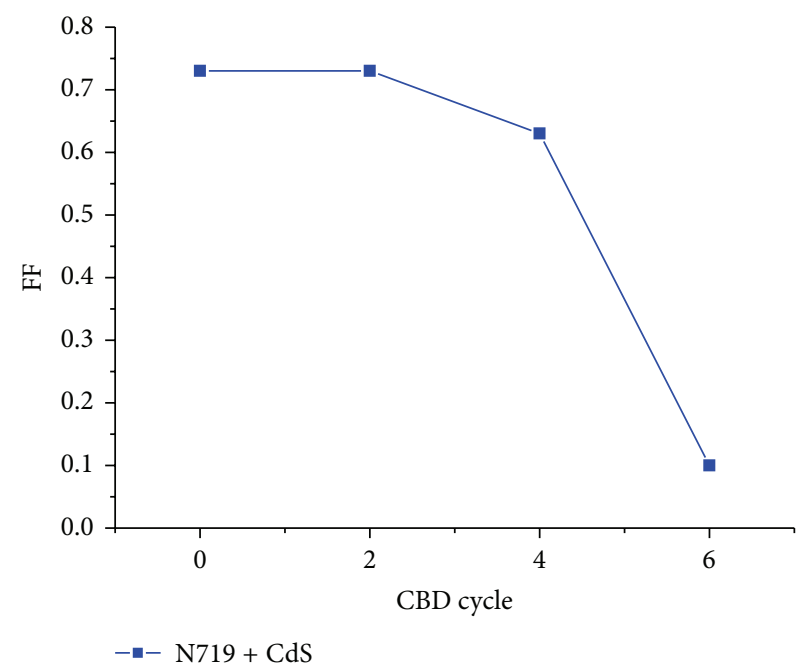

(c)

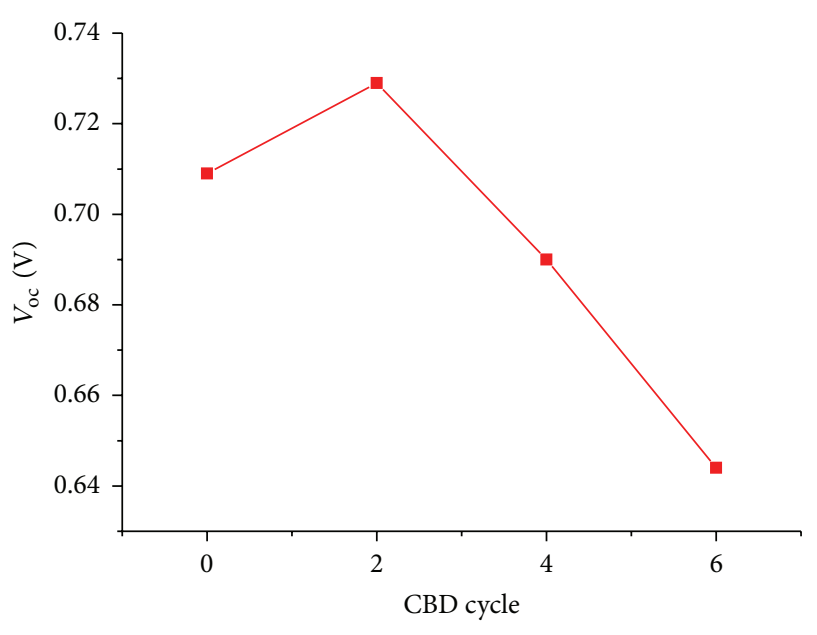

$-\mathbf{- N} 719+\mathrm{CdS}$

(b)

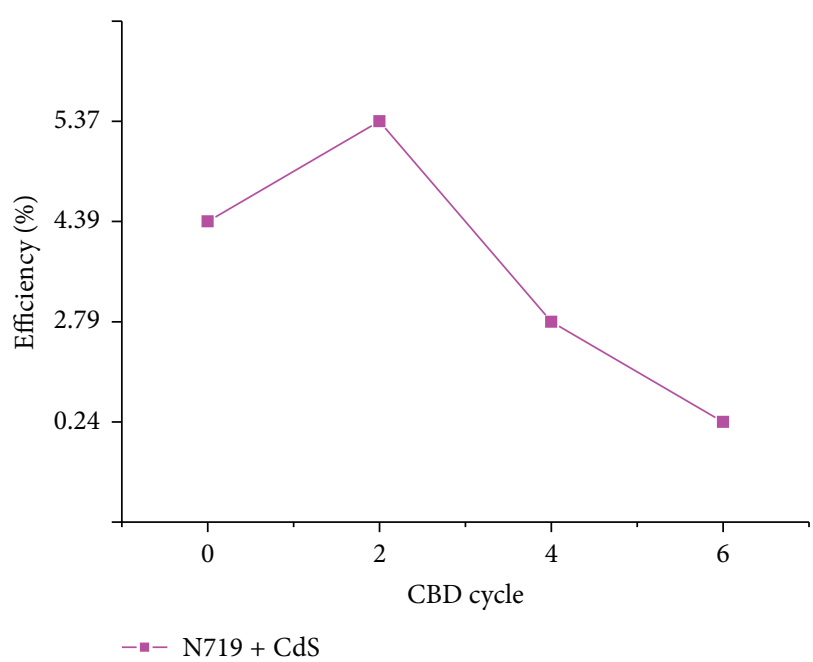

(d)

Figure 5: Trend of the $J_{\text {sc }}, V_{\text {oc }}$, FF, and efficiency with different CBD cycles of cosensitized solar cell.

TABle 2: Parameters of DSSCs constructed with different sensitization conditions.

\begin{tabular}{lcccc}
\hline Sensitization architecture $J_{\text {sc }}\left(\mathrm{mA} / \mathrm{cm}^{2}\right)$ & $V_{\text {oc }}(\mathrm{V})$ & FF & Efficiencies \\
\hline N719 (No QD) & 8.421 & 0.709 & 0.73 & $4.39 \%$ \\
2 & 10.024 & 0.729 & 0.73 & $5.37 \%$ \\
4 & 6.451 & 0.690 & 0.63 & $2.79 \%$ \\
6 & 3.710 & 0.644 & 0.10 & $0.24 \%$ \\
\hline
\end{tabular}

as shown in Table 2 . We can see that, with the assembly of CdS QDs, the efficiency first increases from $4.39 \%$ to $5.37 \%$, but with the CBD cycle of 4 it decreases to $2.74 \%$ and when the cycle is 10 , the efficiency decreases to $0.24 \%$.

The trend of the parameters of the DSSC is shown in Figure 5. From this figure we can see that when the CBD cycle is 2 , the $J_{\mathrm{sc}}, V_{\mathrm{oc}}, \mathrm{FF}$, and efficiency are the best, and when the cycles increase these parameters become smaller.

The phenomena observed above can be explained as follows [9-13]: with the assembly of the CdS QDs, an energy level is inserted between the conduction band of $\mathrm{TiO}_{2}$ and N719 as shown in Figure 6. When the CBD cycle is 2, the conduction band of the CdS is becoming closer to the conduction band of $\mathrm{TiO}_{2}$. Then the electron transition is becoming easier, so the $J_{\mathrm{sc}}$ increases. But with the increase of the CBD cycles (such as 4), the spaces between the $\mathrm{TiO}_{2}$ particles are becoming blocked, and the electrolyte getting into the spaces is becoming harder. What is more is that the electrons can transfer between the $\mathrm{TiO}_{2}$ particles, so the recombination between the electron and hole is becoming easier, so the $J_{\text {sc }}$ decreases. This also causes the FF to decrease and so does the efficiency. So we can see that when CBD cycle is 2 , the best efficiency can be obtained. The performance to other related cosensitized DSSCs is compared in Table 3. 
TABLE 3: The comparisons of the performance to other related cosensitized DSSCs.

\begin{tabular}{|c|c|c|c|c|c|c|c|}
\hline Number & Quantum dot & Dye & Photo anode & $\begin{array}{c}\text { Efficiencies (\%) } \\
\text { (noncosensitizing) }\end{array}$ & $\begin{array}{c}\text { Efficiencies (\%) } \\
\text { (cosensitizing) }\end{array}$ & $\begin{array}{l}\text { Increment of } \\
\text { efficiencies (\%) }\end{array}$ & References \\
\hline 0 & $\mathrm{CdS}$ & N719 & $\mathrm{TiO}_{2}$ & 4.39 & 5.37 & 22.3 & This work \\
\hline 1 & $\mathrm{CdS}$ & N719 & $\mathrm{TiO}_{2}$ & 1.67 & 2.36 & 41.3 & [9] \\
\hline 2 & CdS & N719 & $\mathrm{ZnO} / \mathrm{ZnS}$ & 1.16 & 1.59 & 37.1 & {$[10]$} \\
\hline 3 & $\mathrm{PbS}$ & N719 & $\mathrm{TiO}_{2}$ & 5.95 & 6.35 & 6.7 & {$[11]$} \\
\hline 4 & $\mathrm{Ag}_{2} \mathrm{~S} / \mathrm{CdS}$ & N3 & $\mathrm{TiO}_{2}$ & 0.98 & 1.66 & 69.4 & {$[12]$} \\
\hline 5 & $\mathrm{Ag}_{2} \mathrm{~S}$ & N3 & $\mathrm{TiO}_{2}$ nanotube & 3.64 & 4.40 & 20.9 & {$[13]$} \\
\hline
\end{tabular}

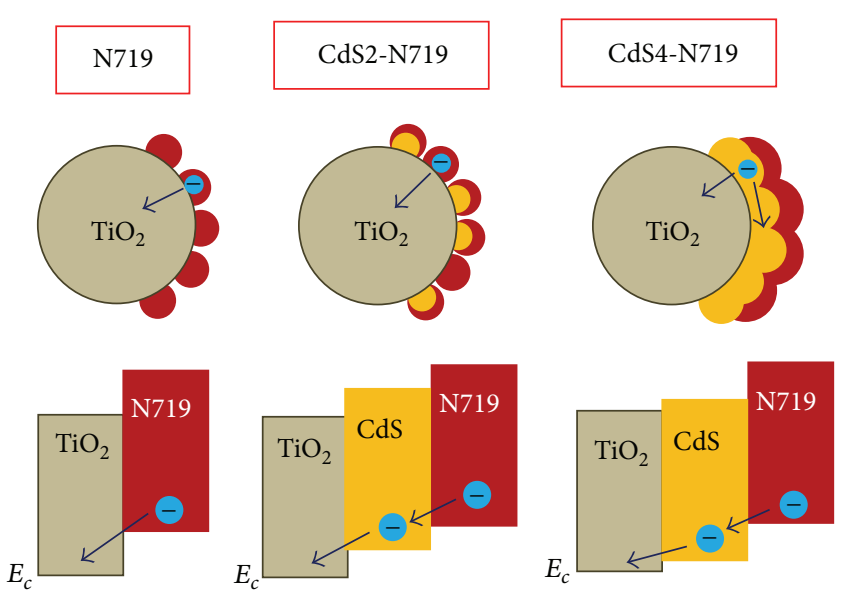

FIGURE 6: Representation of energy level diagram in a cosensitized DSSC by N719 and CdS.

\section{Conclusions}

The CdS QDs alone can sensitize $\mathrm{TiO}_{2}$ films. In order to avoid photo corrosion and electrolyte corrosion, the $\mathrm{TiO}_{2}$ films are cosensitized by CdS and N719. The band gap of CdS QDs was tuned by CBD cycles. With the inserting energy level of $\mathrm{CdS}$, the $V_{\text {oc }}$ and $J_{\text {sc }}$ were increased and so was the efficiency. The efficiency was improved from $4.39 \%$ to $5.37 \%$ when the CBD cycle was 2 .

\section{Conflict of Interests}

The authors declare that there is no conflict of interests regarding the publication of this paper.

\section{Acknowledgments}

This work was partially supported by the Key Project of Beijing Natural Science Foundation (3131001), the Key Project of Natural Science Foundation of China (91233201 and 61376057), the Key Project of Beijing Education Committee Science and Technology Plan (KZ201211232040), the State 863 Plan of MOST of China (2011AA050527), the Beijing National Laboratory for Molecular Sciences (BNLMS201221), the State Key Laboratory of Solid State Microstructures of Nanjing University (M27019), the State Key Laboratory for Integrated Optoelectronics of Institute of Semiconductors of CAS (IOSKL2012KF11), the State Key Laboratory for New Ceramic and Fine Processing of Tsinghua University (KF1210), the Key Laboratory for Renewable Energy and Gas Hydrate of Chinese Academy of Sciences (y207ka1001), the Beijing Key Laboratory for Sensors of BISTU (KF20131077208), and the Beijing Key Laboratory for Photoelectrical Measurement of BISTU (GDKF2013005).

\section{References}

[1] S. Mathew, A. Yella, P. Gao et al., "Dye-sensitized solar cells with $13 \%$ efficiency achieved through the molecular engineering of porphyrin sensitizers," Nature Chemistry, vol. 6, pp. 242-247, 2014.

[2] Y. Wang and N. Herron, "Nanometer-sized semiconductor clusters: materials synthesis, quantum size effects, and photophysical properties," The Journal of Physical Chemistry B, vol. 95, no. 2, pp. 525-532, 1991.

[3] W. W. Yu and X. Peng, "Formation of high-quality CdS and other II-VI semiconductor nanocrystals in noncoordinating solvents: tunable reactivity of monomers," Angewandte Chemie International Edition, vol. 41, no. 13, pp. 2368-2371, 2002.

[4] W. W. Yu, L. Qu, W. Guo, and X. Peng, "Experimental determination of the extinction coefficient of CdTe, CdSe, and CdS nanocrystals," Chemistry of Materials, vol. 15, no. 14, pp. 28542860.

[5] W. A. Tisdale, K. J. Williams, B. A. Timp, D. J. Norris, E. S. Aydil, and X.-Y. Zhu, "Hot-electron transfer from semiconductor nanocrystals," Science, vol. 328, no. 5985, pp. 1543-1547, 2010.

[6] G. S. Philippe, “Quantum dots: a new quantum state?” Nature Materials, vol. 4, pp. 653-654, 2005.

[7] J. S. Hong, J. Zhao, and L. Jiang, "Effect of structural modification on photodynamic activity of hypocrellins," Photochemistry and Photobiology, vol. 74, no. 2, pp. 143-148, 2001.

[8] T. Ganesh, R. S. Mane, G. Cai, J.-H. Chang, and S.-H. Han, " $\mathrm{ZnO}$ nanoparticles-cds quantum dots/n3 dye molecules: dual photosensitization," Journal of Physical Chemistry C, vol. 113, no. 18, pp. 7666-7669, 2009.

[9] X. Lin, K. Yu, G. Lu, J. Chen, and C. Yuan, "Atomic layer deposition of $\mathrm{TiO}_{2}$ interfacial layer for enhancing performance of quantum dot and dye co-sensitized solar cells," Journal of Physics D: Applied Physics, vol. 46, no. 2, 2012. 
[10] D. Han, Y. Sun, J. Yang et al., "Enhanced performance of dye/QDs cosensitized solar cells via Förster resonance energy transfer," Electrochimica Acta, vol. 109, pp. 291-297, 2013.

[11] Y. Liu and J. Wang, "Co-sensitization of $\mathrm{TiO}_{2}$ by $\mathrm{PbS}$ quantum dots and dye N719 in dye-sensitized solar cells," Thin Solid Films, vol. 518, no. 24, pp. e54-e56, 2010.

[12] H. K. Jun, M. H. Buraidah, M. M. Noor et al., "Application of LiBOB-based liquid electrolyte in co-sensitized solar cell," Optical Materials, vol. 36, no. 1, pp. 151-158, 2013.

[13] G. Ji, Z. Liu, D. Guan, and Y. Yang, "Ag2S quantum dots and N3 dye co-sensitized $\mathrm{TiO}_{2}$ nanotube arrays for a solar cell," Applied Surface Science, vol. 282, pp. 695-699, 2013. 

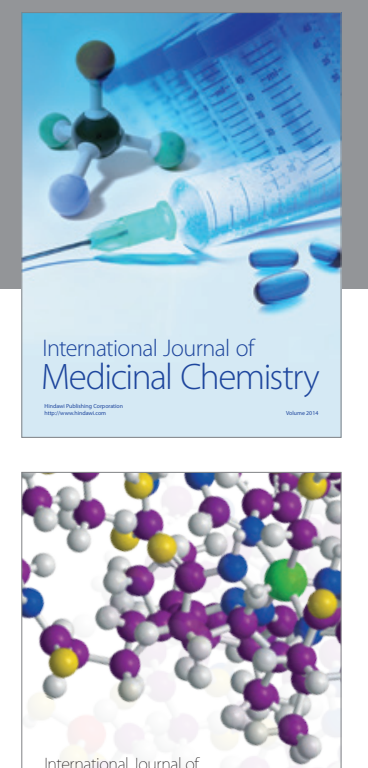

\section{Carbohydrate} Chemistry

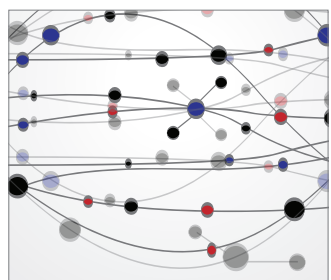

The Scientific World Journal
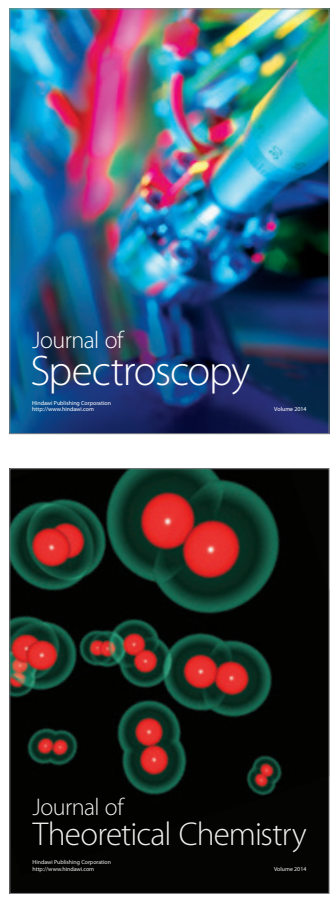
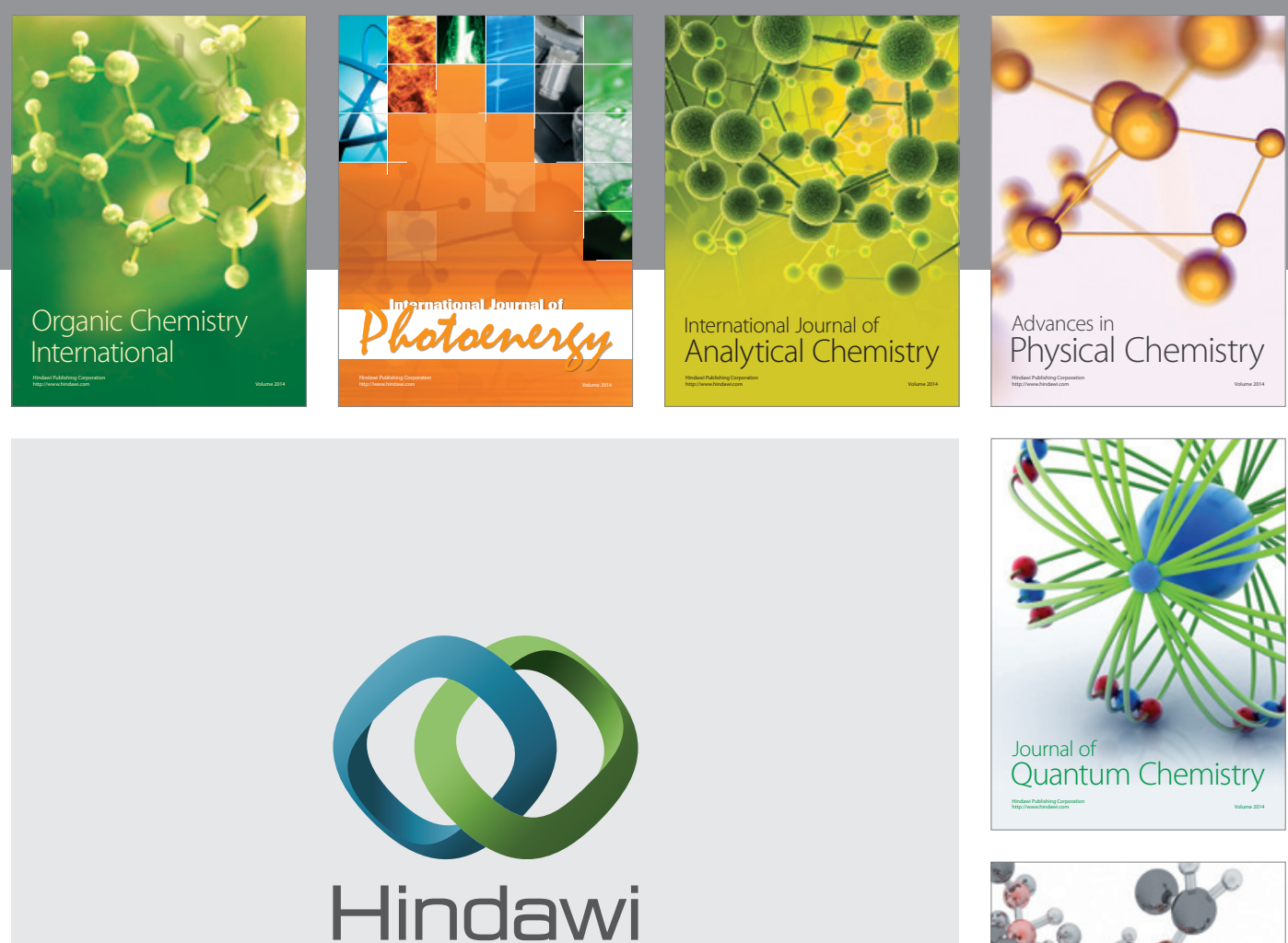

Submit your manuscripts at

http://www.hindawi.com

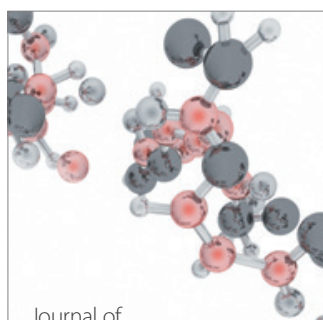

Analytical Methods

in Chemistry

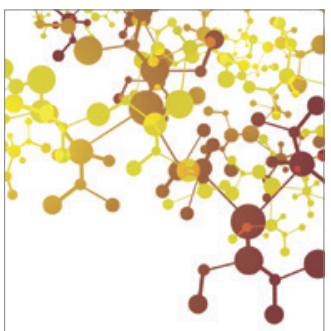

Journal of

Applied Chemistry

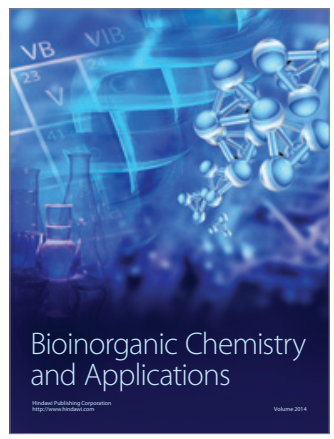

Inorganic Chemistry
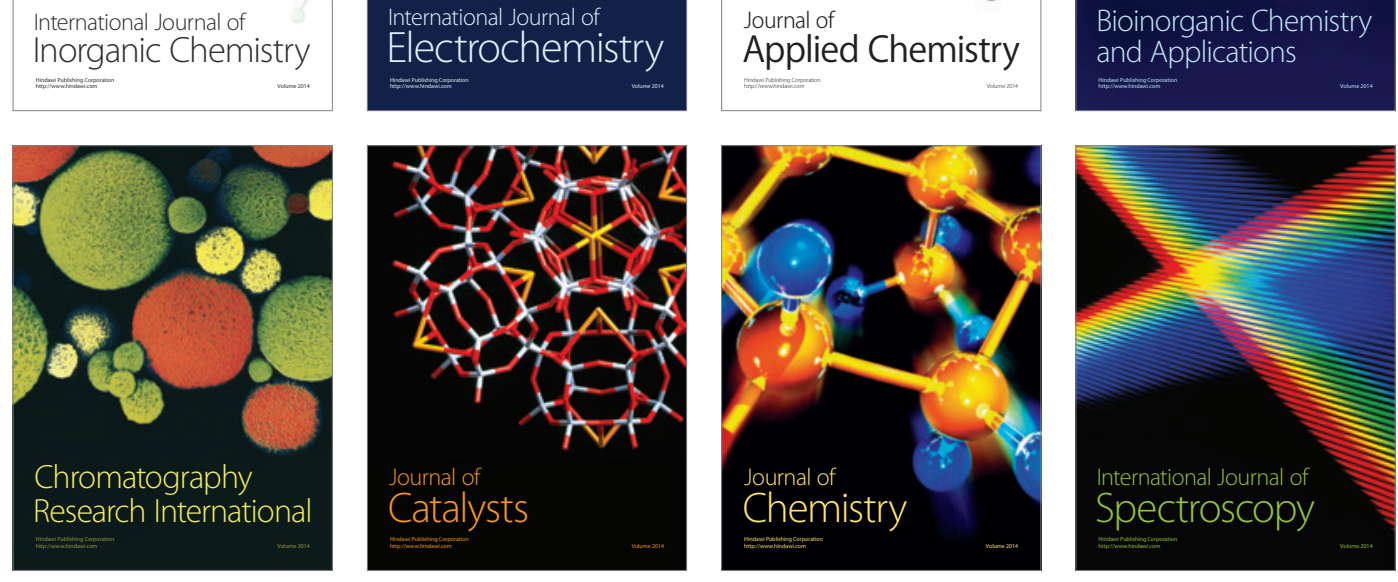